\title{
Moisture management behaviour of modified polyester wool fabrics
}

\author{
Pawan Kumar, Sujit Kumar Sinha* and Subrata Ghosh
}

\author{
* Correspondence: sinhask@nitj.ac.in \\ Department of Textile Technology, \\ National Institute of Technology, \\ Jalandhar 144011, India
}

\begin{abstract}
To support the thermo regularity system of human body in completely changed environment and physical activity the functional clothing must create a stable microclimate next to the skin. The present study deals with the moisture transport and moisture management behaviour of polyester wool yarn and knitted fabric treated with two types of enzyme viz; alkaline protease enzyme and acidic protease enzyme. The prime object of this study was to enhance the moisture transport and moisture management properties of yarn and fabric for use in active wear. The results reveal superior wicking behaviour by alkaline protease enzyme treatment, while superior moisture vapour permeability with acidic protease enzyme treatment. Moisture management properties of alkaline protease enzyme treated fabric gives better result, ranging its grade from very good to excellent with higher absorption rate, one way transport capacity and spreading speed. Analysis of variance (ANOVA) was applied to test statistical significance level of all effects.
\end{abstract}

Keywords: Wool; Wicking; Moisture vapour permeability; Moisture management properties; Proteolytic alkaline \& acidic enzyme; Knitted fabric

\section{Introduction}

The use of wool in active sportswear is growing rapidly. Fine and good quality wool in apparel and hosiery offers a scope of enhancing performance and comfort when engaged in physical activity. Wool has unique elastic and heat insulation properties besides high moisture absorption capacity (about $35 \%$ by weight).

The fibre is composed of two types of cells, viz; the internal hydrophilic cells of the cortex and hydrophobic cuticle cells that form a sheath around the fibre. Cuticle of wool fibre is responsible for itching during wear, restricting its use in tropical atmosphere. The hydrophilic interior that confers unique moisture management properties (MMP), results in enhanced wearer comfort (Simpson et al., 2002). Removal of cuticle by a suitable method can help to get rid of itching problem thereby widening its use (http://www.campaignforwool.co.nz, 2012).

The physiological comfort from an active wear influences the performance of wearer and such clothing needs to be designed to facilitate both moisture \& heat dissipation process. The fabric for active wear is specially constructed with specific geometry, fibre packing in constituent yarns and its structure to achieve optimum dissipation of heat and moisture at high metabolic rates (Das 2010b, Shishoo 2005, Goldman 1988). Introduction of selective porosity can significantly influence the moisture transport 
properties and thermo physiological responses in fabrics made from it (Mukhopadhyay et al. 2011, Das 2009).

Moisture vapour transportation deciding thermo-physiological characteristics is a critical determinant for wear comfort while sweating. The clothing materials play the important role of transporting moisture from the skin to the atmosphere.

Enzymes are highly selective catalysts which accelerates both the rate and specificity of metabolic reactions. The utilization of enzymes in the textile industry has been known and applied commercially for many years; viz; use of desizing of cotton and to produce indigo abrasion on denim. Proteolytic enzymes have the potential to hydrolyze the wool's peptide bonds and enzymatic hydrolysis can be tailored to optimize the effect. Protease enzyme has been in use for wool and silk processing, and can be tailored to increase the effect of enzyme reaction (Cardamone 2002, El-Sayed 2002). With the hydrolysis of wool the scales on its surface may be removed.

Selection of fibre type and geometry of the yarn \& fabric can influence heat \& moisture transfer. Both natural and synthetic fibres are used in the control of thermo-physiological comfort, but polyester fibre has founds its maximum usage in technical textile sector. Despite its poor absorbency, polyester is the most common fibre used for active wear presumably due to improved moisture transport behaviour through wicking (Das et al. 2010a, Das et al. 2008, Ishtiaque 2001).

In this study, an attempt has been made to create additional porosity in yarn and fabric by selective removal of one component by enzymatic treatment. A comparative assessment was made for wicking in yarn and moisture management behaviour of fabric after enzyme treatment in alkaline and acidic medium.

\section{Theoretical background of wicking in yarn}

Wicking is the spontaneous flow of a liquid in a porous substrate driven by capillary forces. The liquid moves into a porous medium by the capillary pressure i.e., the differential pressure across the liquid-air interface due to the curvature of meniscus in the narrow confines of the pores. The magnitude of the capillary pressure, which decides the capillary height, is commonly given by the Laplace equation as applied to idealized capillary tubes (Adamson 1967):

$$
p=\frac{2 \gamma \cos \theta}{r_{c}}
$$

where $p=$ Capillary pressure, $\mathrm{r}_{\mathrm{c}}=$ Capillary radius, $\gamma=$ Surface tension, $\theta=$ Contact angle at the liquid-solid-air interface.

When the liquid and the material are kept unchanged at a particular atmospheric condition, the capillary height will depend on the geometry of yarn and hence, in the present case, the diameter of the capillary. The arrangement of fibres in a staple yarn provides wide variability in the size and shape of the passage for the liquid to flow. When the capillary cross sectional diameter changes, the interfacial speed and contact angle changes. The change in dynamic contact angle will in turn affect the capillary force driving the liquid flow. The obstruction, due to migration of fibres generated in the path of the flow is also expected to affect the capillary rise. Wicking height for a given yarn is related by the formula (Lord, 1974). 


$$
h \propto\left(K_{c} K_{p^{\prime}}\right)^{-1}
$$

Both $K_{c}$ and $K_{p}$, are the function of twist multiplier, type of fibre, yarn structure, and packing fraction as well as fibre migration.

\section{Materials and Methods}

Polyester/wool (90/10) yarn of $56^{\mathrm{s}} \mathrm{Nm}$ (17.9 Tex) with 890 twist per meter was produced for the study. Polyester fibre of 1.4 denier and length $56 \mathrm{~mm}$ and merino wool of average diameter $21 \mu \mathrm{m}$ (4.08 denier) and $70 \mathrm{~mm}$ length was used for spinning of yarn on worsted ring spinning system. Single jersey knitted fabric $(W P I \times C P I=35 \times 58$, GSM $=135$, Tightness factor $=14.9$, Loop length $=2.82 \mathrm{~mm}$ ) was made on Delha socks knitting machine of diameter $8.9 \mathrm{~cm}$ using 22 gauge. Protease enzyme was used in both alkaline (ALPE) \& acidic (ACPE) medium.

\section{Enzyme treatment and design of experiment}

Enzyme treatment was given yarn to both yarns and fabrics. To avoid entanglement of yarns, hank of yarn was made with the help of wrap reel and was tied, at places, with filament. Three levels of enzyme concentration, $\mathrm{pH}$ and treatment time were used for enzyme treatment in each medium. These parameters are expected to influence the extent of hydrolysis of wool fibre and hence packing of yarn. A three variable Box and Behnken factorial design (Table 1) was used to study the combined interaction of these factors on various properties of yarn and fabric. To study the detailed interaction effect of different variables, a three-level and three-variable factorial design was used to get the response surface equation (Table 2). Two way analysis of variance (ANOVA) was made on experimental results using Statistica 6 software. A 95\% level significance was taken and so the value of $\mathrm{p}$ less than 0.05 is considered an indication of statistically significant result.

\section{Evaluation of yarn diameter, packing density and wicking properties}

Yarn diameter was measured using a leica microscope. The specific volume of yarn and yarn packing fraction were calculated by using the following formulae (Das et al., 2008):

Yarn specific volume, $\frac{\mathrm{cm}^{3}}{g}=\frac{\pi d^{2}}{4 \times 10^{-5} \times \text { tex of yarn }}$, Yarn packing fraction $=v_{f} / v_{y}$

$\mathrm{d}=$ diameter of yarn, $v_{f}=$ specific volume of fibre, $v_{y}=$ specific volume of yarn

Wicking of yarn was measured in accordance with DIN 53924 (1978). The rate of change of height of liquid/unit time was observed through the eyepiece of a travelling

Table 1 Box and Behnken design for three variables

\begin{tabular}{|c|c|c|c|c|c|c|c|c|c|c|c|c|c|c|c|}
\hline$\underline{\text { Standard order }}$ & 1 & 2 & 3 & 4 & 5 & 6 & 7 & 8 & 9 & 10 & 11 & 12 & 13 & 14 & 15 \\
\hline Enzyme $\% X_{1}$ & -1 & 1 & -1 & 1 & -1 & 1 & -1 & 1 & 0 & 0 & 0 & 0 & 0 & 0 & 0 \\
\hline $\mathrm{pH} X_{2}$ & -1 & -1 & 1 & 1 & 0 & 0 & 0 & 0 & -1 & 1 & -1 & 1 & 0 & 0 & 0 \\
\hline Treatment Time $X_{3}$ & 0 & 0 & 0 & 0 & -1 & -1 & 1 & 1 & -1 & -1 & 1 & 1 & 0 & 0 & 0 \\
\hline
\end{tabular}


Table 2 Actual values of variable corresponding to coded levels for alkaline and acidic protease enzyme

\begin{tabular}{|c|c|c|c|c|c|c|}
\hline \multirow[t]{2}{*}{ Variable $\downarrow$} & \multicolumn{3}{|c|}{ Alkaline enzyme } & \multicolumn{3}{|c|}{ Acidic enzyme } \\
\hline & -1 & 0 & +1 & -1 & 0 & +1 \\
\hline Enzyme\% $\left(X_{1}\right)$ & 3 & 5 & 7 & 3 & 5 & 7 \\
\hline $\mathrm{pH}\left(X_{2}\right)$ & 8 & 10 & 12 & 3 & 4.5 & 6 \\
\hline Treatment Time [T] $\{\min \}.\left(X_{3}\right)$ & 60 & 90 & 120 & 60 & 90 & 120 \\
\hline
\end{tabular}

microscope. Procion Blue MR dye (1\%) was added in the liquid to facilitate accuracy of reading, while maintaining the surface tension \& viscosity of the liquid unchanged. The reading was taken in one minute interval up to ten minutes time. The yarn was clamped and a mass of $5 \mathrm{~g}$ was attached to keep it straight. At least 30 readings were taken for each sample to get the result at $95 \%$ confidence limit.

\section{Conditioning of sample}

Conditioning of the yarn and fabric sample was done at tropical atmosphere of $27^{\circ} \mathrm{C} \pm$ $2{ }^{\circ} \mathrm{C}$ and $65 \% \pm 2 \%$ R.H and the number of reading was decided according to the variation in the sample so that $95 \%$ confidence limit can be achieved.

\section{Moisture vapour permeability}

Water vapour permeability was measured as per BS 7209 using evaporative dish method. The specimen under test was sealed over the open mouth of a dish containing water placed in the standard atmospheric condition for testing. After 24 hours, the weight of the system and the rate of water vapour transfer through the fabric were calculated using the formula

$$
W V P=\frac{24 \times M}{A t} g / m^{2} / \text { day }
$$

Loss of water $(\mathrm{g})$ through fabric, $\mathrm{A}=$ Internal area of the fabric $\left(\mathrm{m}^{2}\right), \mathrm{t}=$ Time of testing (24 hours).

\section{Moisture management testing}

Knitted fabric (untreated and treated) samples were tested on SDL ATLAS M290 Moisture Management Tester (MMT) according to AATCC Test Method 195-2009.

To measure moisture management properties of fabrics accurately and objectively moisture management tester, as shown in Figure 1 was used.

In this tester fabric specimen is held flat by top and lower sensors at a certain pressure. A certain known volume of a pre defined test solution is then put into the sweat gland and introduced onto the top surface of the fabric. This instrument in integrated with a computer with moisture management software which records the change in resistance between each couple of proximate metal rings individually at the top and lower sensors.

The salted solution transfers in three directions after arriving on the fabric specimen top surface i.e. spreading outward on top surface transfer from top surface to the bottom surface and spreading outward on bottom surface. The resistance of each couple of proximate metal rings changes due to solution, which can conduct electricity. 


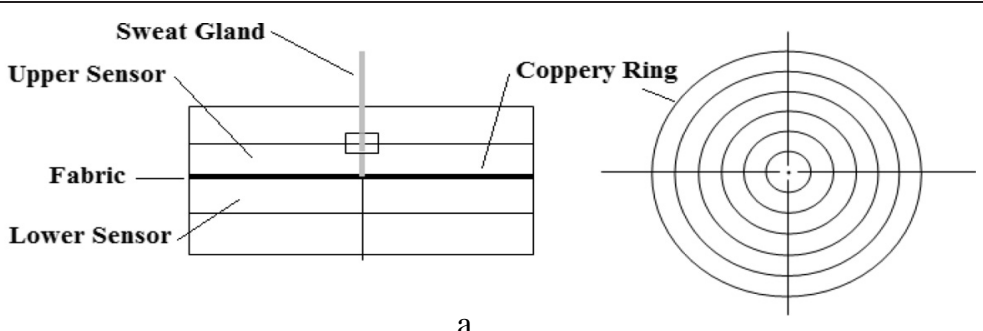

a

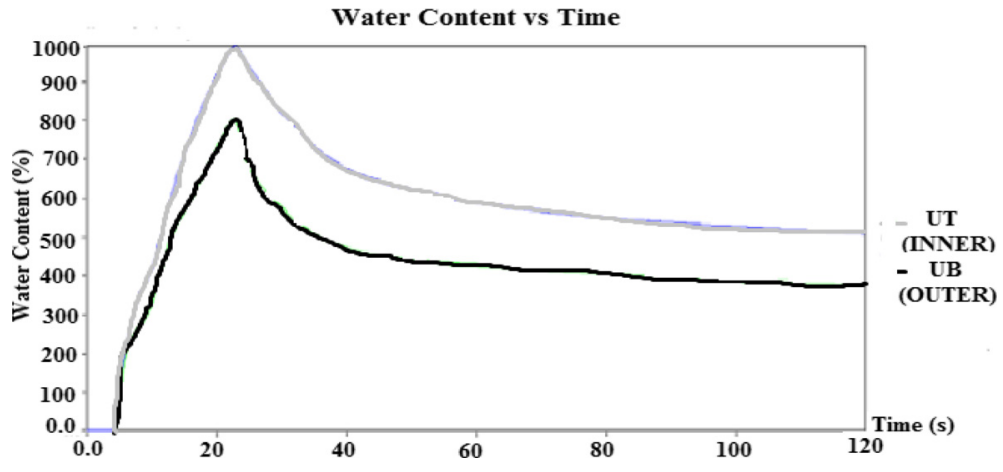

\begin{tabular}{|c|c|c|}
\hline & Top Surface & Bottom surface \\
\hline Wetting Time & 8.06 & 34.92 \\
\hline Absorption Rate $(\% / \mathrm{sec})$ & 40.59 & 3.34 \\
\hline Max. Wetted & 5.0 & 5.0 \\
\hline Spreading Speed (mm/sec) & 0.41 & 0.14 \\
\hline One way transport capability & \multicolumn{2}{|c|}{1094.42} \\
\hline Description & \multicolumn{2}{|c|}{ MMT } \\
\hline & b
\end{tabular}

Figure 1 (a) Sketch of moisture management sensor \& (b) water content curve.

Grading according to the moisture management tester result is shown in Table 3 . While Figure 1(b) gives a typical water content curve.

\section{Results and discussion}

\section{Wicking in yarn}

The relationship of wicking is represented in Figure 2. It is observed that the wicking of alkaline protease enzyme (ALPE) treated yarn is higher than that of the acidic protease enzyme treated (ACPE) treated yarn. From the enzyme \% and $\mathrm{pH}$ interaction of surface plot, it is observed that higher level of enzyme \% \& higher level of $\mathrm{pH}$ in ALPE and for lower level of $\mathrm{pH}$ \& higher level of enzyme \% gives higher wicking, In enzyme \%, treatment time, $\mathrm{pH} \&$ treatment time interaction there was not much change in wicking height in both treatment.

After the enzyme treatment in alkaline medium a loss in weight was observed while the loss was marginal after treatment in acidic medium. Results of physical properties and wicking in yarns before and after alkaline and acidic protease enzyme treatment are given in Table 4. The $\mathrm{p}$ value of ANOVA test result for wicking in yarn is given in Table 5. Treatment with acidic protease enzyme led to more reduction in packing density and higher increase in specific volume and diameter than alkaline protease enzyme 
Table 3 Grading specifications

\begin{tabular}{|c|c|c|c|c|c|c|}
\hline \multirow[t]{2}{*}{ Index } & & \multicolumn{5}{|l|}{ Grade } \\
\hline & & 1 & 2 & 3 & 4 & 5 \\
\hline \multirow[t]{4}{*}{ Wetting Time (s) } & Top & $>=120$ & $20-119$ & $5-19$ & $3-5$ & $<3$ \\
\hline & & No Wetting & Slow & Medium & Fast & Very Fast \\
\hline & Bottom & $>=120$ & 20-119 & $5-19$ & $3-5$ & $<3$ \\
\hline & & No Wetting & Slow & Medium & Fast & Very Fast \\
\hline \multirow[t]{4}{*}{ Absorption Rate (\%/s) } & Top & $0-10$ & $10-30$ & $30-50$ & $50-100$ & $>100$ \\
\hline & & Very Slow & Slow & Medium & Fast & Very Fast \\
\hline & Bottom & $0-10$ & $10-30$ & $30-50$ & $50-100$ & $>100$ \\
\hline & & Very Slow & Slow & Medium & Fast & Very Fast \\
\hline \multirow[t]{4}{*}{ Max. Wetted Radius (mm) } & Top & $0-7$ & $7-12$ & $12-17$ & $17-22$ & $>22$ \\
\hline & & No Wetting & Small & Medium & Fast & Very fast \\
\hline & Bottom & $0-7$ & $7-12$ & $12-17$ & $17-22$ & $>22$ \\
\hline & & No Wetting & Small & Medium & Fast & Very fast \\
\hline \multirow[t]{4}{*}{ Spreading Speed (mm/sec) } & Top & $0-1$ & $1-2$ & $2-3$ & $3-4$ & $>4$ \\
\hline & & Very Slow & Slow & Medium & Fast & Very Fast \\
\hline & Bottom & $0-1$ & $1-2$ & $2-3$ & $3-4$ & $>4$ \\
\hline & & Very Slow & Slow & Medium & Fast & Very Fast \\
\hline \multirow[t]{2}{*}{ One Way Transport Capacity } & & $<-50$ & $-50-100$ & $100-200$ & $200-400$ & $>400$ \\
\hline & & Very poor & Poor & Good & Very Good & Excellent \\
\hline \multirow[t]{2}{*}{ OMMC } & & $0-0.2$ & $0.2-0.4$ & $0.4-0.6$ & $0.6-0.8$ & $>0.8$ \\
\hline & & Very poor & poor & good & Very Good & Excellent \\
\hline
\end{tabular}

treatment. The reduction in packing density and increase in diameter of the yarns expected to change the dimension of the capillary.

The wicking height in the yarns was observed to reduce after enzyme treatment. The reduction however, is more in case of acidic protease enzyme treated yarns than that for alkaline protease enzyme treated yarns.

As a result of enzyme treatment following changes in the arrangement of fibres is expected: The loss in weight indicates complete or partial dissolution of wool fibre. Partial dissolution is expected to affect the cuticle while a complete dissolution leads to an open structure. Presence of any residual portion may cause a change in the geometry of the capillary. As the structure becomes open due to removal of one component, a possibility of collapsing the structure cannot be ignored, which may further affect the size and shape of the capillary and hence liquid flow through it. On the other hand, a nominal weight loss by acidic enzyme probably ensures mere removal of cuticle. Accordingly, the extent of structural change through such treatment is expected to be less. Wicking in a yarn can be facilitated by the inter fibre space, surface geometry and property of the constituent fibres. A hydrophobic fibre assists movement of liquid more than a hydrophilic fibre; the later, incidentally allows movement of liquid only after saturation.

The partial removal of cuticle by acidic enzyme treatment might have helped more absorption of liquid by the wool component which may cause its diameter to increase. On absorption, swelling of wool causes displacement of fibre position in the yarn. The treatment temperature may also influence the shrinkage of wool that results the 


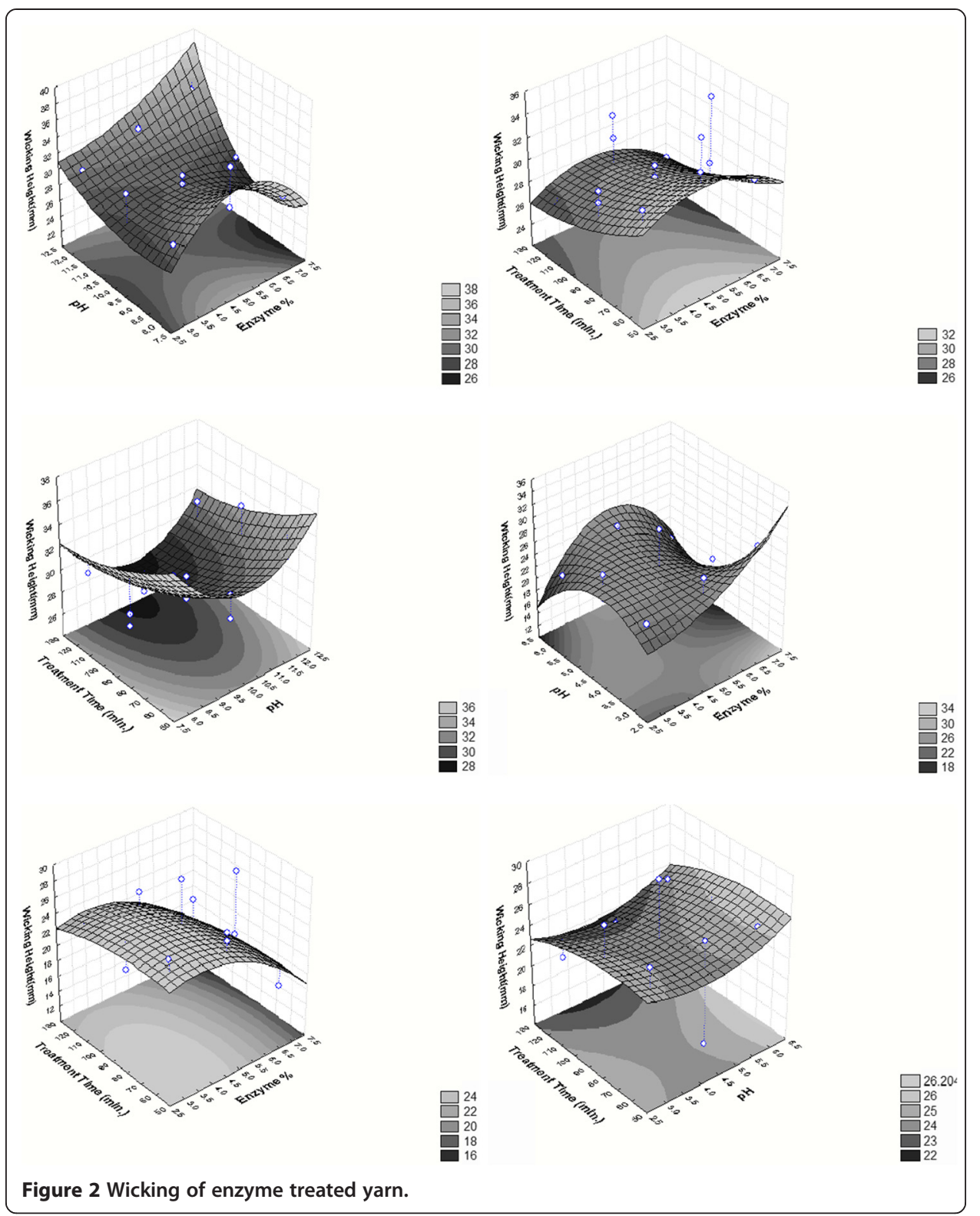

diameter to increase. The stressed fibres might undergo relaxation of stress causing the inward transverse pressure applied by them to reduce.

Typical SEM images and cross-section views of the yarns before and after enzymatic treatment are given in Figures 3 and 4. It is evident from the figure that the treatment has not only resulted diameter of the yarns to increase but also resulted some degree of loosening of the structures. An observation of the cross-sectional image suggests a reduction in packing density in yarns after both the treatments.

The internal absorption of liquid and subsequent swelling of fibre cannot support wicking and hence the enzyme treatment of yarn in acidic medium shows poor wicking behaviour. Enzyme treatment in alkaline medium caused almost complete removal of cuticle and cortex as well. The wicking height is the maximum where weight reduction (indicating removal of wool component) after treatment is the maximum. However, in other cases the wicking height is somewhat less presumably due to the presence of a 
Table 4 Physical properties and wicking of enzyme treated yarn

\begin{tabular}{|c|c|c|c|c|c|c|}
\hline \multirow{2}{*}{$\begin{array}{l}\text { Sample } \\
\text { no. }\end{array}$} & \multicolumn{2}{|c|}{ Diameter (mm) } & \multicolumn{2}{|c|}{ Packing fraction } & \multicolumn{2}{|c|}{ Wicking height of yarn $(\mathrm{mm})$} \\
\hline & ALPE & ACPE & ALPE & ACPE & ALPE & ACPE \\
\hline 1 & 0.195 & 0.234 & 0.43 & 0.31 & 29 & 23 \\
\hline 2 & 0.193 & 0.238 & 0.43 & 0.30 & 30 & 21 \\
\hline 3 & 0.195 & 0.231 & 0.45 & 0.32 & 28 & 27 \\
\hline 4 & 0.185 & 0.234 & 0.46 & 0.31 & 34 & 19 \\
\hline 5 & 0.204 & 0.247 & 0.41 & 0.27 & 35 & 26 \\
\hline 6 & 0.186 & 0.243 & 0.47 & 0.28 & 32 & 25 \\
\hline 7 & 0.181 & 0.226 & 0.52 & 0.31 & 30 & 21 \\
\hline 8 & 0.196 & 0.235 & 0.42 & 0.28 & 32 & 24 \\
\hline 9 & 0.189 & 0.232 & 0.48 & 0.32 & 31 & 26 \\
\hline 10 & 0.193 & 0.246 & 0.45 & 0.25 & 29 & 16 \\
\hline 11 & 0.195 & 0.227 & 0.44 & 0.30 & 26 & 22 \\
\hline 12 & 0.183 & 0.234 & 0.50 & 0.31 & 26 & 20 \\
\hline 13 & 0.185 & 0.248 & 0.50 & 0.27 & 29 & 21 \\
\hline 14 & 0.186 & 0.236 & 0.49 & 0.30 & 30 & 29 \\
\hline 15 & 0.186 & 0.245 & 0.48 & 0.28 & 28 & 21 \\
\hline Avg. & 0.190 & 0.237 & 0.46 & 0.29 & 30 & 23 \\
\hline Un-treated & 0.176 & & 0.54 & & 35 & \\
\hline
\end{tabular}

portion of the wool component which creates hindrance in the movement of liquid by creating obstruction and facilitating some degree of absorption.

Moisture transport and moisture management properties of fabric Water vapour permeability

The liquid vapour transmission through a fabric depends considerably on the micro porous nature of the structure. Necessary care should be taken during the design of an active wear to introduce as many pores/micro-pores as possible, helping transportation of heat and liquid mass through it. Transmission of water vapour from the body of the wearer is particularly important as it can effectively help in managing thermal condition of the body as well. Table 6 shows the comparison of water vapour permeability of the knitted fabrics. The $\mathrm{p}$ value of ANOVA test result for factors and interaction of water vapour permeability is given in Table 5 . From the Figure 5 it is observed that ACPE treated fabric gives higher water vapour permeability than the ALPE treated fabric. In both the treatment middle level of enzyme \% and middle level of $\mathrm{pH}$ and higher level of treatment time gives higher moisture permeability.

Improvement of water vapour permeability is more in case of acidic protease enzyme treated fabric than alkaline protease enzyme treated fabric. Treatment in acidic medium resulted more increase in yarn diameter, specific volume and reduction in packing density. This reduced packing density allows more volume of water vapour to pass through it when the fabric structure remains unchanged. Flow of air generally more through the passage of least resistance. The water vapour will also pass through such paths of least resistance through liquid/vapour movement can also be assisted by micro channels formed in yarns. Air flow through micro channels may require some initial 
Table 5 ANOVA analysis of moisture transport and moisture management properties

\begin{tabular}{|c|c|c|c|c|c|c|c|c|c|c|c|c|c|c|c|c|c|c|c|c|c|c|}
\hline \multirow{3}{*}{$\begin{array}{l}\text { Property } \rightarrow \\
\text { Treatment } \rightarrow\end{array}$} & \multicolumn{4}{|c|}{ Moisture transport properties } & \multicolumn{18}{|c|}{ Moisture management properties } \\
\hline & \multicolumn{2}{|c|}{ Wicking in Yarn } & \multicolumn{2}{|l|}{ WVP } & \multicolumn{4}{|c|}{ Wetting Time } & \multicolumn{4}{|c|}{ Absorption Rate } & \multicolumn{4}{|c|}{ Max. Wetted Radius } & \multicolumn{4}{|c|}{ Spreading Speed } & \multicolumn{2}{|l|}{ OWTC } \\
\hline & ALPE & ACPE & ALPE & ACPE & ALPE & & ACPE & & ALPE & & ACPE & & ALPE & & ACPE & & ALPE & & ACPE & & ALPE & ACPE \\
\hline Effect $\downarrow$ & & & & & Top & Bottom & Top & Bottom & Top & Bottom & Top & Bottom & Top & Bottom & Top & Bottom & Top & Bottom & Top & Bottom & Top & Bottom \\
\hline Enzyme \% & $0.21^{\#}, \mathrm{~ns}^{*}$ & $0.53, \mathrm{~ns}$ & $0.1, \mathrm{~ns}$ & 0.53 , ns & $0.10 \mathrm{~ns}$ & $0.21 \mathrm{~ns}$ & $0.02, \mathrm{~s}$ & $0.19, \mathrm{~ns}$ & $0.58, \mathrm{~ns}$ & $0.55, \mathrm{~ns}$ & $0.08 \mathrm{~ns}$ & $0.69 \mathrm{~ns}$ & $0.06 \mathrm{~ns}$ & $0.00 \mathrm{~s}$ & $0.2, \mathrm{~ns}$ & $0.03 \mathrm{~s}$ & $0.76 \mathrm{~ns}$ & $0.09 \mathrm{~ns}$ & $0.71 \mathrm{~ns}$ & $0.21 \mathrm{~ns}$ & $0.60 \mathrm{~ns}$ & $0.01 \mathrm{~s}$ \\
\hline $\mathrm{pH}$ & $0.02, s^{* *}$ & $0.53, \mathrm{~ns}$ & $0.00, \mathrm{~s}$ & $0.02, s$ & $0.01 \mathrm{~s}$ & $0.50 \mathrm{~ns}$ & $0.02, \mathrm{~s}$ & $0.00, \mathrm{~s}$ & $0.85, \mathrm{~ns}$ & $0.00, \mathrm{~s}$ & $0.18 \mathrm{~ns}$ & $0.38 \mathrm{~ns}$ & $0.07 \mathrm{~ns}$ & $0.00 \mathrm{~s}$ & $0.04 \mathrm{~s}$ & $0.17 \mathrm{~ns}$ & $0.09 \mathrm{~ns}$ & $0.39 \mathrm{~ns}$ & $0.19 \mathrm{~ns}$ & $0.31 \mathrm{~ns}$ & $0.64 \mathrm{~ns}$ & $0.13 \mathrm{~ns}$ \\
\hline$\Pi$ & 0.06 , ns & 0.81 , ns & $0.04, \mathrm{~s}$ & $0.15, \mathrm{~ns}$ & $0.20 \mathrm{~ns}$ & $0.60 \mathrm{~ns}$ & $0.04, \mathrm{~s}$ & $0.07, \mathrm{~ns}$ & $0.39, \mathrm{~ns}$ & 0.09 , ns & $0.09 \mathrm{~ns}$ & $0.58 \mathrm{~ns}$ & $0.16 \mathrm{~ns}$ & $0.00 \mathrm{~s}$ & $0.23 \mathrm{~ns}$ & $0.56 \mathrm{~ns}$ & $0.16 \mathrm{~ns}$ & $0.59 \mathrm{~ns}$ & $0.27 \mathrm{~ns}$ & $0.19 \mathrm{~ns}$ & $0.57 \mathrm{~ns}$ & $0.00 \mathrm{~s}$ \\
\hline Enzyme\%\& pH & $0.15, \mathrm{~ns}$ & $0.38, \mathrm{~ns}$ & $0.72, \mathrm{~ns}$ & 0.99 , ns & $0.64 \mathrm{~ns}$ & $0.40 \mathrm{~ns}$ & 0.12 , ns & $0.02, \mathrm{~s}$ & $0.95, \mathrm{~ns}$ & $0.04, \mathrm{~s}$ & $0.07 \mathrm{~ns}$ & $0.64 \mathrm{~ns}$ & $0.02 \mathrm{~s}$ & $0.15 \mathrm{~ns}$ & $0.08 \mathrm{~ns}$ & $0.05 \mathrm{~ns}$ & $0.58 \mathrm{~ns}$ & $0.18 \mathrm{~ns}$ & $0.25 \mathrm{~ns}$ & $0.21 \mathrm{~ns}$ & $0.56 \mathrm{~ns}$ & $0.00 \mathrm{~s}$ \\
\hline
\end{tabular}

${ }^{\#} p$-value, ${ }^{*} n s-$ not significant if $p>0.05,{ }^{*}$ significant if $p<0.05$ at $95 \%$ confidence limit. 


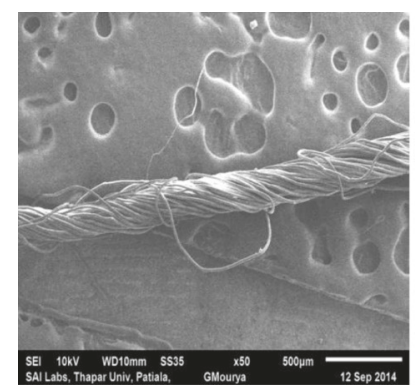

a

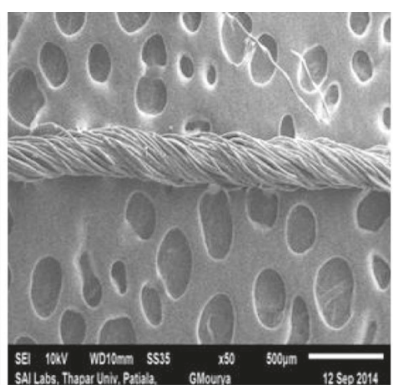

b

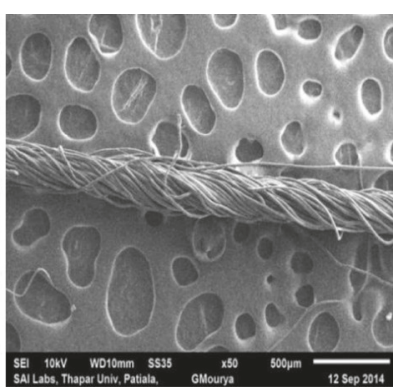

C

Figure 3 SEM images (a) reference yarn (b) ALPE yarn (c) ACPE yarn.

force while liquid flow through such micro channels may be assisted by a drag by the fibre. Moisture vapour transport, among other factors, decides the suitability of a fabric for its use as active wear. In order to maintain thermal balance of the body during any activity even in normal condition, the heat produced by the process of metabolism, needs to be dissipated. As a result of heat generation, sweat glands produce perspiration, which remains in the skin and clothing interface, both in liquid and vapour form. The wearer will feel comfortable when such perspiration is moved away from that interfacial zone. Transportation of liquid perspiration can be assisted by wicking while that in vapour form is to be diffused through the clothing. The passage through the pores, adsorption and migration along the fibre surface, transmission by forced convection, absorption, transmission and desorption by fibre are important parameters influencing diffusion processes of water vapour (Das et al., 2007).

In the present case, possibility of first two mechanisms is more. However, the possibility of absorption cannot be neglected fully due to the presence of residual wool component.

The vapour transmission through a fabric will also be influenced by the resistance offered by the fabric. The flow of water vapour passing through the fabric is given by (Fourt et al., 1951):

$$
Q=\frac{1}{R} \times D(\Delta c) A t
$$

where, $\mathrm{Q}$ is the amount of water vapour in $\mathrm{g}, \mathrm{R}$ (a function of pores/openness) is the resistance offered by the fabric, $D$ is the diffusion coefficient, $\Delta_{C}$ is difference in vapour concentration, $\mathrm{A}$ is area in $\mathrm{cm}^{2}$ and $\mathrm{t}$ is time in $\mathrm{s}$.

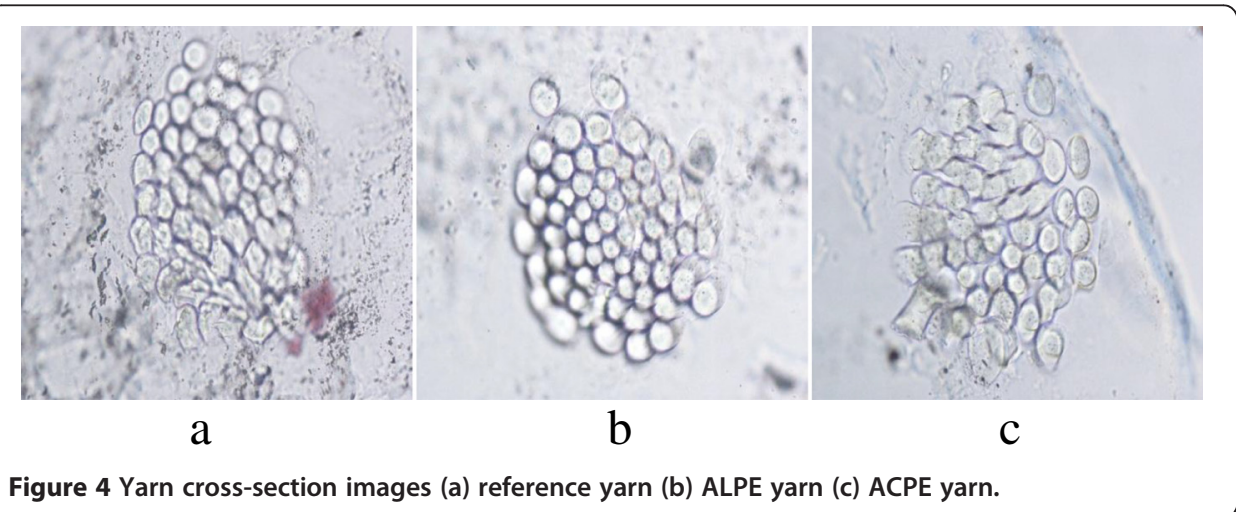




\section{Table 6 Water vapour permeability of enzyme treated fabric}

Water vapour permeability $\left(\mathrm{g} / \mathrm{m}^{2} /\right.$ day $)$

Treatment Sample

condition

1

ALPE

$2-3$

$\begin{array}{lll}4 & 5 & 6\end{array}$

7

8

9

10

11

12

13

14

ACPE

$\begin{array}{lllllll}624.5 & 615.8 & 614.6 & 614.1 & 612.8 & 618.7 & 612.9\end{array}$

602.9

613.6

620.7

744.7

713.4

722.3

723.7

Untreated 


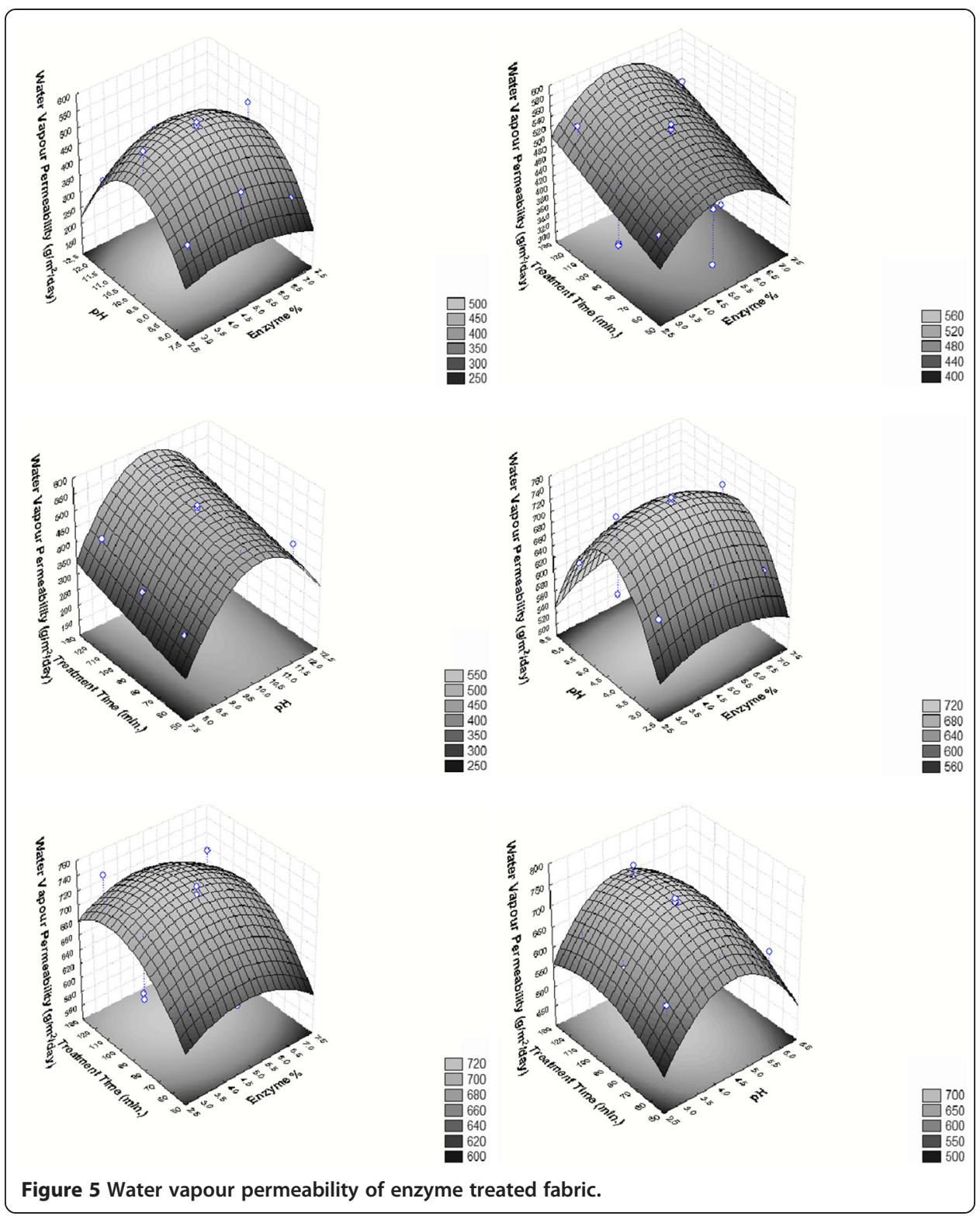

In the present study, fibre and its characteristics, yarn structure and fabric structure are the variables that can affect water vapour permeability.

The enzyme treatment of the fabric involves complete/partial removal of one component, i.e., wool. This implies a change in the composition of the yarns and fabric structure. Complete or partial removal of one component leads to a change in the yarn structure. Partial removal on the other hand, is expected to influence the transmission primarily by absorption induced pulling force. The openness of a structure due to removal of a component not only helps transmission but also it provides additional space, which in turn helps transportation of vapour/liquid.

\section{Wetting time (Top and Bottom)}

Wetting is the replacement of a solid-liquid, solid-air or liquid-air interface with a liquid-liquid interface. Wetting time is the time period in which top and bottom 


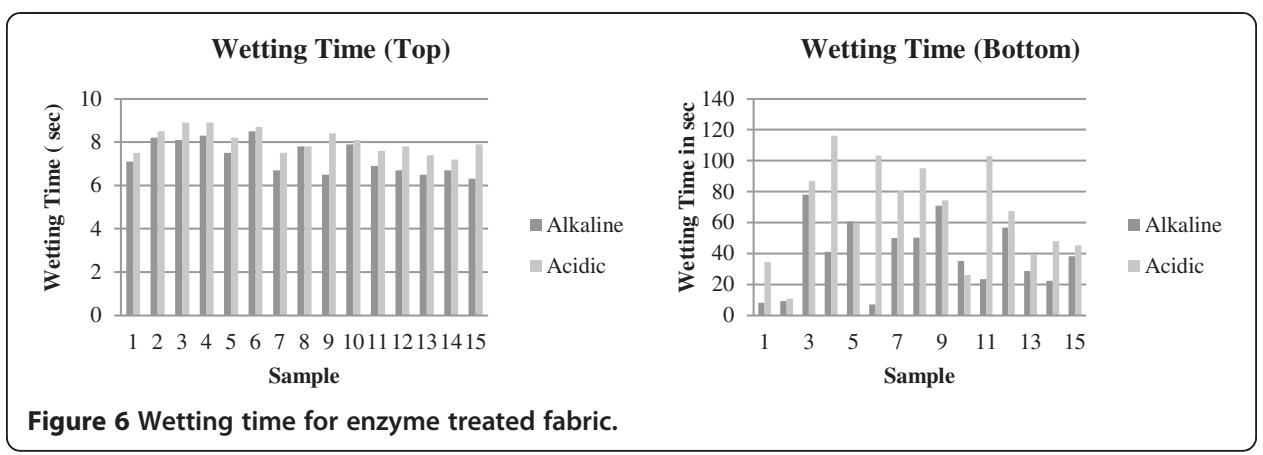

surfaces of the fabric just start to be wetted. Figure 6 shows the comparison of wetting time by absorbency drop test of the treated fabrics. The p value of ANOVA test result for wetting time (top \& bottom) is given in Table 5 .

The effect of change in enzyme concentration, $\mathrm{pH}$ and treatment time on the wetting time was found significant. These factors lead to the variation in the degree of removal of wool fibre and accordingly the wetting behaviour of fabric will be influenced primarily by the polyester component. The wettability index of polyester is low and removal/ reduction of wool component will cause dominance of polyester.

It is observed from the figure that both top and bottom wetting time is less for alkaline enzyme treated fabrics than acidic enzyme treated fabrics. The effective removal of wool component and possible surface damage of polyester component by alkaline treatment may be responsible for resulting less wetting time. Effective removal of wool component by alkaline treatment will make the structure more open facilitating liquid transfer. Hence bottom wetting time for alkaline treated fabrics is much less.

\section{Absorption rate (Top and Bottom)}

Absorption of liquid by a textile substrate indicates the degree of transfer of liquid on its surface. The absorption of liquid by a fabric may be influenced by the type of fibre, yarn structure, fabric structure, and openness in the structure.

It may be observed from the Figure 7 that the top absorption rate for acidic enzyme treated fabric is higher while the bottom absorption rate for alkaline enzyme treated fabric is higher.

Treatment with enzyme in acidic medium results in nominal loss of weight causing ineffective removal of wool and possible removal of cuticle. The remaining part is more hygroscopic ensuring higher surface absorption rates. On the other hand, effective

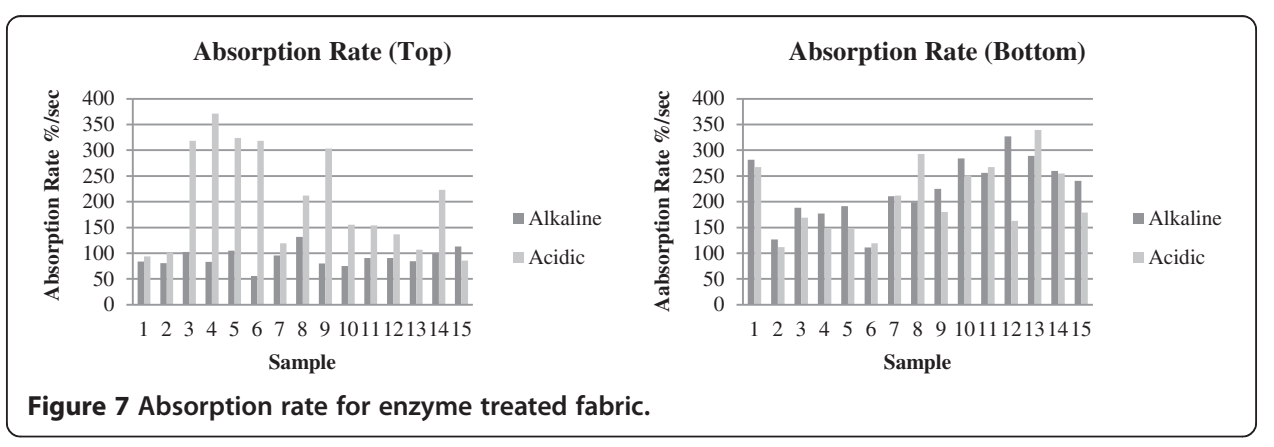




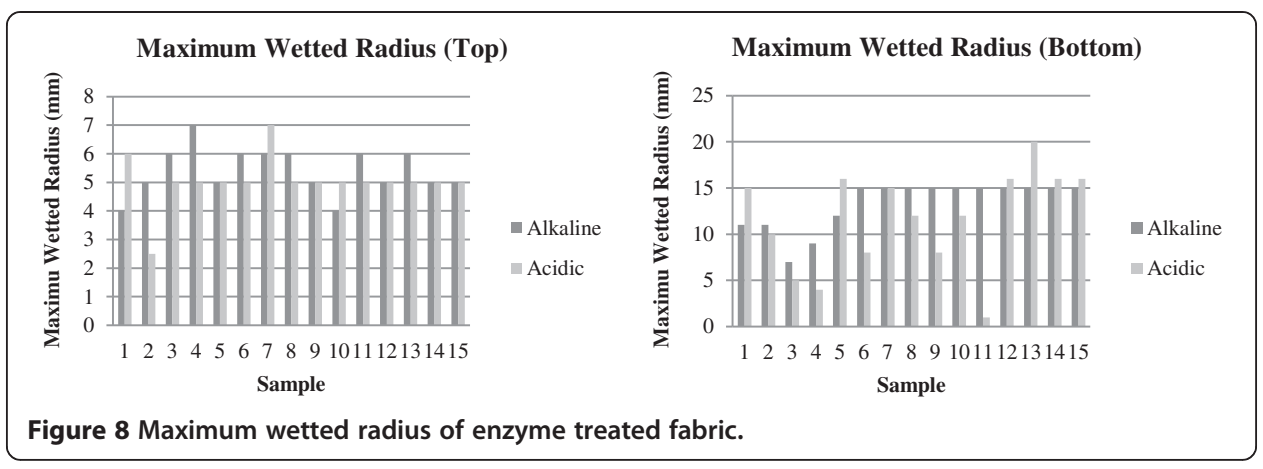

removal of wool by enzyme treatment in alkaline medium resulted more open structure allowing faster transfer of liquid from top to bottom surface. Ability of faster transfer of liquid results in higher bottom surface absorption rate.

\section{Maximum wetted radius (Top and Bottom)}

Maximum wetted radius influences the drying behaviour of fabric. A fabric giving higher wetted radius should show better drying behaviour. It is observed from the Figure 8 that both top and bottom wetted radius in ALPE treated fabric is generally more. The structure which allows more dispersion of liquid should show higher radius. Cortex of wool can hold maximum liquid. Acidic enzyme treatment exposed the cortex of wool which promotes absorption rather than dispersion. The alkaline enzyme treatment ensures removal of wool thereby making the structure more open. Such an open structure encourages transmission and dispersion of liquid leading to higher wetting radius. The $\mathrm{p}$ value of ANOVA test result for wetted radius (top \& bottom) is given in Table 5.

\section{Spreading speed (Top and Bottom)}

Spreading speed refers to the ability of the fabric to allow the liquid movement outward in its plane. A fibre with less holding capacity of liquid will allow such trans-planer movement. The comparative result of spreading speed in fabrics treated with enzyme in alkaline and acidic medium is represented in Figure 9. It is observed that ALPE treated sample resulted higher spreading speed.

Effective removal of wool component for ALPE treated samples caused higher porosity in the structure and reduced holding power. While ineffective removal by ACPE

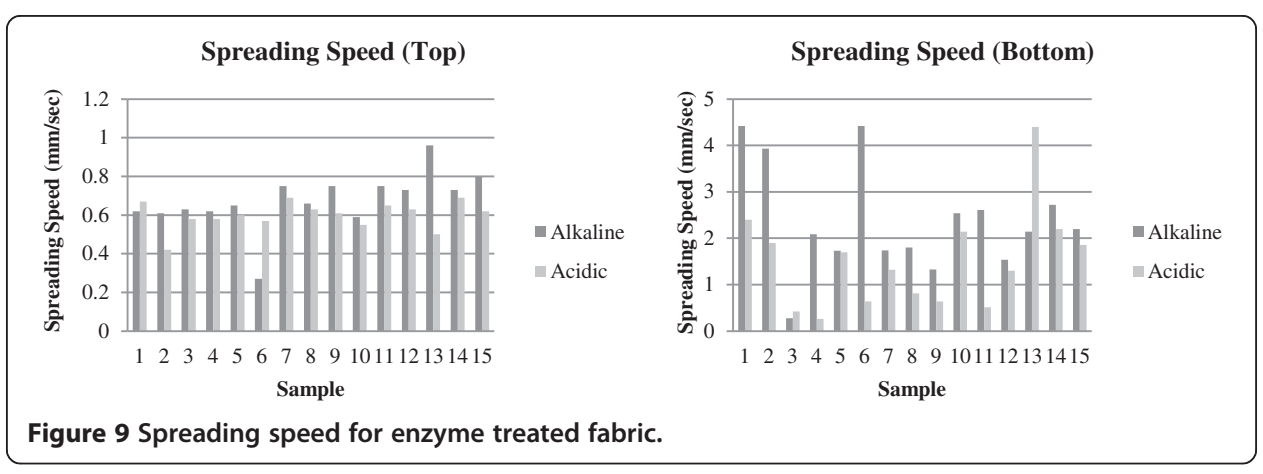




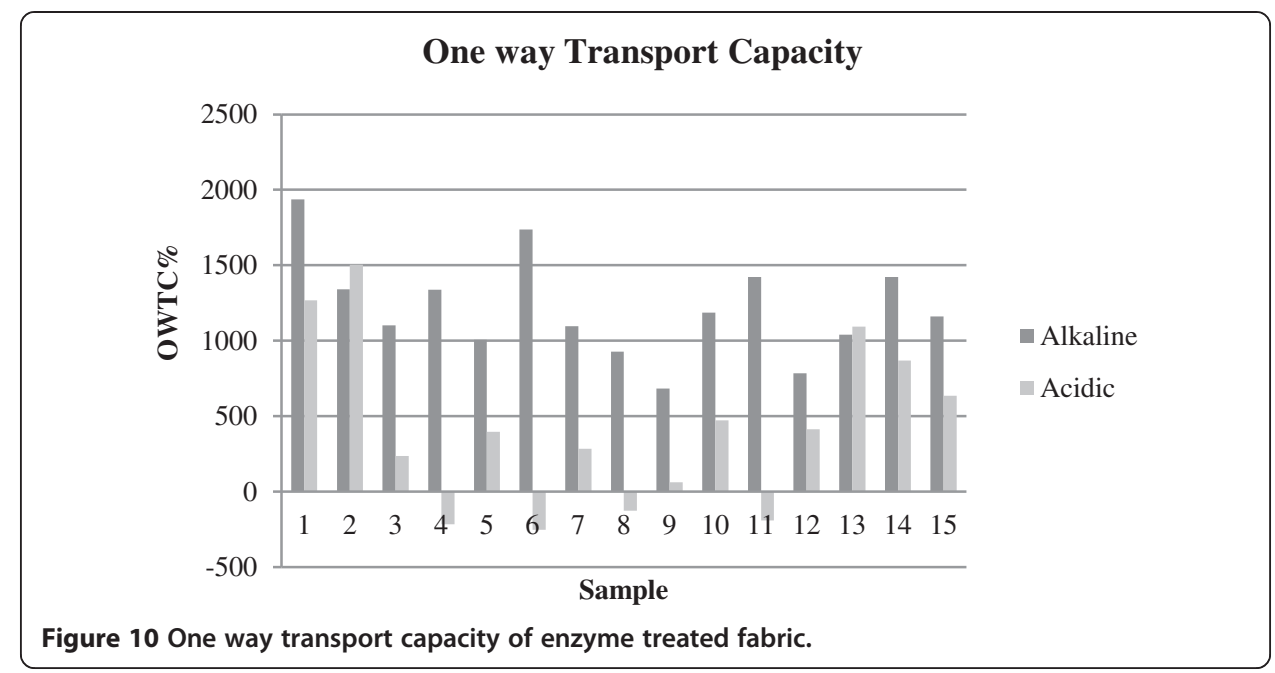

treatment has increased liquid holding power by wool component, thereby restricting trans-planner movement of liquid. The $\mathrm{p}$ value of ANOVA test result for spreading speed (top \& bottom) has been shown in Table 5 .

\section{One way transport capacity (OWTC)}

One way transport capacity is the difference in the cumulative moisture content between the two surfaces of the fabric in the unit testing time. Alkaline enzyme treated fabric shows better OWTC than the acidic enzyme treated fabric as given in Figure 10.

\section{Overall moisture management capacity (OMMC)}

This an index to indicate the overall ability of the fabric to manage the transport of liquid moisture, which includes three aspects of performance, viz; spreading speed hence drying speed, moisture absorption rate of bottom side, one -way liquid transport ability.

Higher overall moisture management capacity indicates better overall moisture transport ability of the fabric. Moisture management grading of alkaline protease enzyme

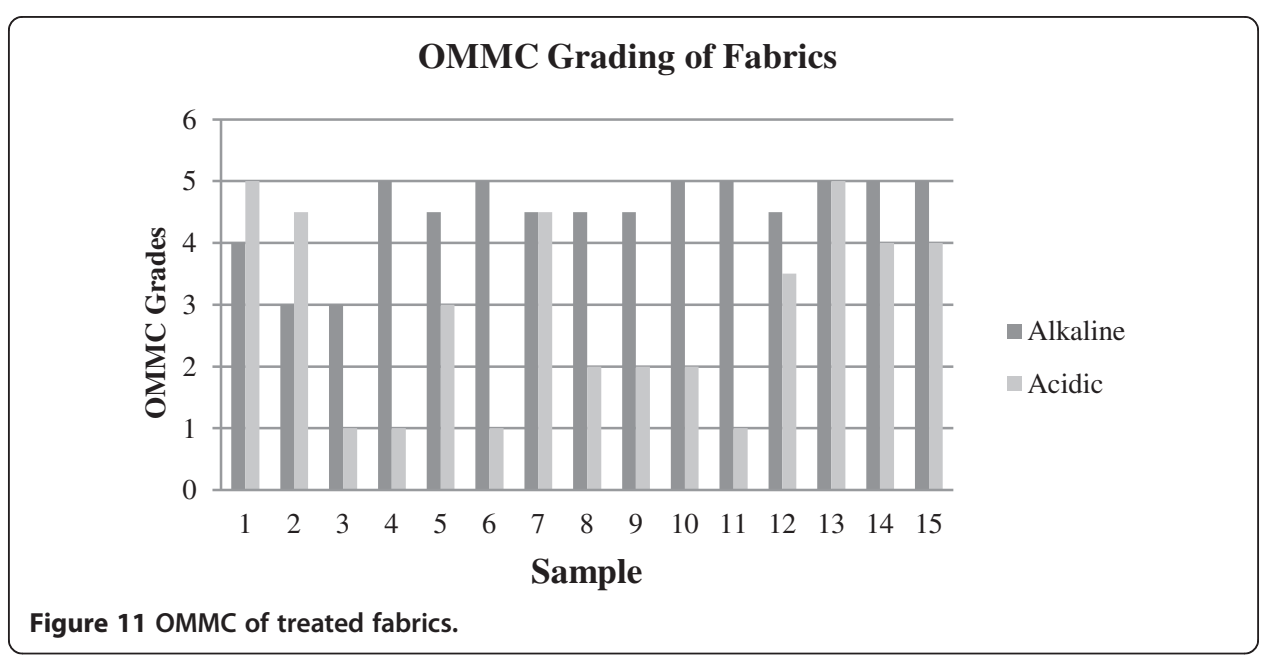


treated fabric was higher than acidic protease enzyme treated fabric. The OMMC can be expressed by the relationship (Hu et al., 2005).

$$
O M M C=0.25 M A R_{b}+0.5 O W T C+0.25 S S_{b}
$$

Moisture management fabric has been ranked from 1-5 on the basis of moisture management parameters. Rank 1 indicates poor moisture management behaviour while rank 5 represents the best.

Figure 11 shows the OMMC grading of the samples under study. The average OMMC grading of most of the ALPE treated fabrics is more than that of ACPE treated fabrics. It is also clear from the figure that the overall grading for ACPE is fair while the grading of ALPE treated fabrics is excellent. This leads to the conclusion that moisture management behaviour of ALPE treated fabric is better than that of ACPE treated fabrics.

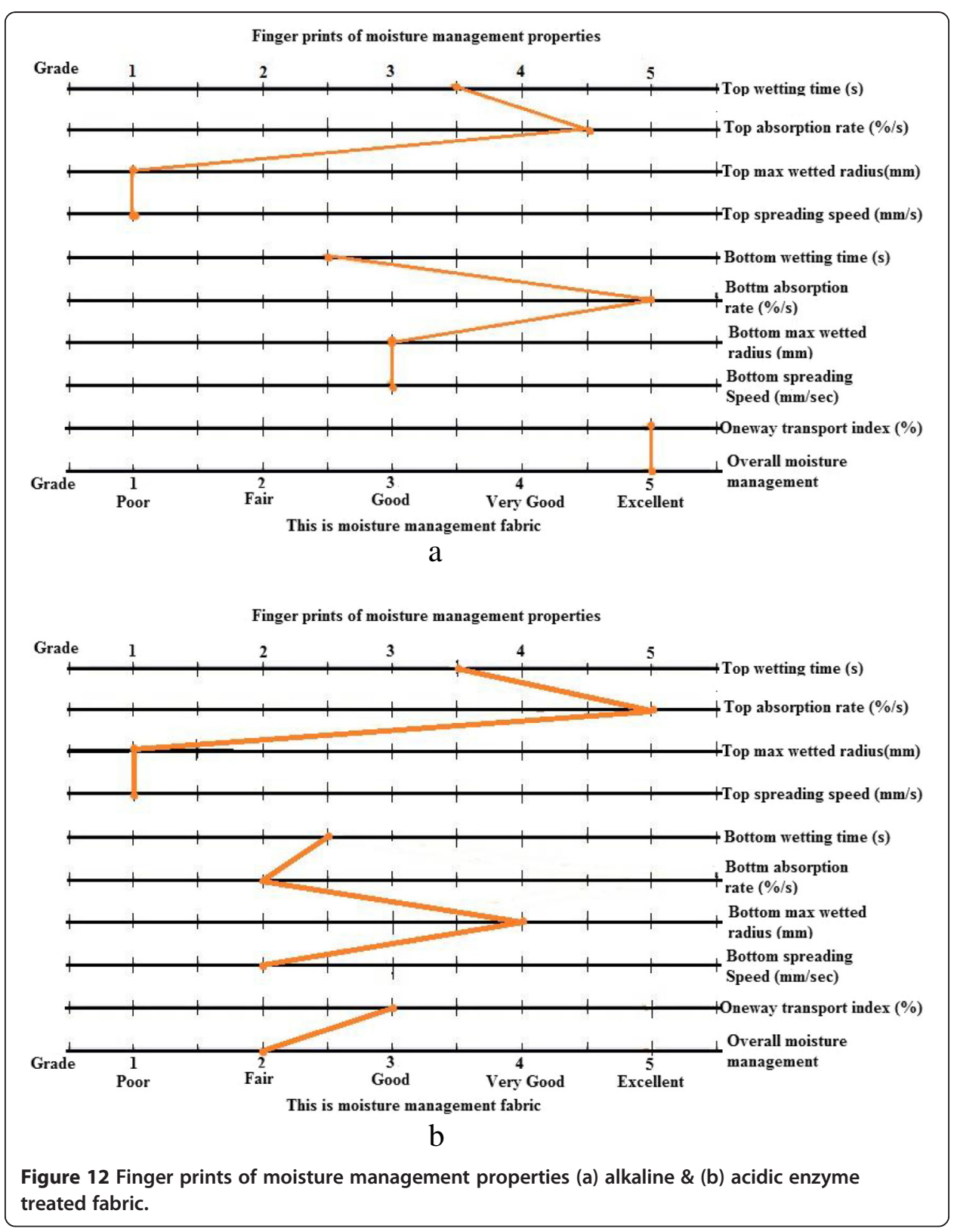


The finger print of (Figure 12) moisture management properties confers an ALPE fabric as excellent while ACPE is identified as fair as regard to their moisture management properties. However, both types of fabrics were conferred as moisture management fabric.

\section{Conclusion}

Wicking, moisture vapour permeability and moisture management properties can characterize the moisture transport behaviour of polyester wool yarn and knitted fabrics. Treatment with enzyme caused changes in both yarn and fabric characteristics. The porosity and diameter of yarn increased while packing density reduced on enzymatic treatment. Fabric moisture management behaviour, on the other hand, showed remarkable improvement after enzyme treatment. Alkaline protease enzyme treated yarns displayed improved wicking behavior than acidic protease enzyme treated yarn due to near complete removal of wool and hence dominance of polyester. The moisture vapour transportation and moisture management properties of alkaline protease enzyme treated fabric were superior than acidic protease enzyme treated fabric. The finger print result is an index for characterization of fabric for its moisture management behaviour. Though the finger print results of both the fabrics indicated as moisture management fabrics, the rating for alkaline protease enzyme treated fabric was very good to excellent.

Competing interests

The authors declare that they have no competing interests.

Authors' contributions

PK, SKS and SG conceived and designed the experiments. PK performed the experiments, analyzed the data in consultation with SKS \& SG. All the authors together finalized the manuscript.

Received: 26 July 2014 Accepted: 26 January 2015

Published online: 25 March 2015

\section{References}

Adamson, AW (1967). Physical Chemistry of surfaces. New York: John Wiley Publication.

Cardamone, JM (2002). Proteolytic activity of aspergillus flavus on wool, AATCC Rev., May, 30-35.

Das, A (2010b). Modification of Textile Yarn Structure for Functional Application. In R Alagirusamy \& A Das (Eds.), Technical Textile Yarns, Industrial and Medical Applications (pp. 91-110). New Delhi: WoodHead Publisher India Pvt. Ltd.

Das, A, \& Alagirusamy, R (2010a). Science in Clothing Comfort (pp. 1-10). New Delhi: WoodHead Publisher India Pvt. Ltd.

Das, B, Kothari, VK, Fanguiro, R, \& Arauja, M (2007). Moisture Transmission Through Textiles. Part II: Evaluation Methods and Mathematical Modelling. Autism Research Journal, 7(3), 194-216.

Das, A, Ishtiaque, SM, \& Singh, RP (2008a). Packing of Micro-Porous Yarns Part I: Optimization of Yarn Characteristics. Journal of the Textile Institute, 99(2), 147-155.

Das, B, Das, A, Kothari, VK, Fanguiero, R, \& De Araujo, M (2008b). Effect of Fibre Diameter and Cross-Sectional Shape on Moisture Transmission through Fabrics. Fibres and Polymers, 9(2), 225-231.

Das, A, Ishtiaque, SM, \& Singh, RP (2009). Packing of Micro-porous Yarns Part II: Optimization of Fabric Characteristics. Journal of the Textile Institute, 100(3), 207-217.

El-Sayed, H, Hamed, RR, \& Kantouch, A (2002). Enzyme-Based Feltprofing of Wool, AATCC Review, January.

Fourt, L, Sookne, MA, Frishman, D, \& Harris, M (1951). The Rate of Drying of Fabrics. Textile Research Journal, 21(1), 26-33.

Goldman, R (1988). The Handbook on clothing, Biomedical Effects of Military Clothing and Equipment Systems. Brussels: Report NATO Research Study Group.

Hu, J, Li, Y, Yeung, K-w, Wong, S, Anthony, W, \& Xu, W (2005). Moisture Management Tester: A Method to Characterize Fabric Liquid Moisture Management Properties. Textile Research Journal, 75(1), 57-62.

Ishtiaque, SM (2001). Engineering Comfort. Asian Textile Journal, 10(11), 36-39.

Lord, P.R (1974). A comparison of the Performance of Open-End and Ring Spun Yarns in Terry Towelling, Textile Res. J., July, 44, 516-522.

Mukhopadhyay, A, Ishtiaque, SM, \& Uttam, D (2011). Impact of Structural Variations in Hollow Yarn on Heat and Moisture Transport Properties of Fabrics. Journal of the Textile Institute, 102(8), 700-712.

Performance of Marino Wool, Retrieved 11 December 2012, from http://www.campaignforwool.co.nz

Shishoo, R (2005). Textile in Sports, The Textile Institute (pp. 1-8). Cambridge, England: CRC Press, WoodHead Publishing Limited.

Simpson, WS, \& Crawshaw, G (2002). Wool: Science and Technology. Cambridge, United Kingdom: CRC press, Woodhead Publisher. 